\title{
Accumbens Shell-Hypothalamus Interactions Mediate Extinction of Alcohol Seeking
}

\author{
E. Zayra Millan, Teri M. Furlong, and Gavan P. McNally \\ School of Psychology, The University of New South Wales, Sydney, New South Wales 2052, Australia
}

The nucleus accumbens shell (AcbSh) is required to inhibit drug seeking after extinction training. Conversely, the lateral hypothalamus $(\mathrm{LH})$, which receives projections from AcbSh, mediates reinstatement of previously extinguished drug seeking. We hypothesized that reversible inactivation of AcbSh using GABA agonists (baclofen/muscimol) would reinstate extinguished alcohol seeking and increase neuronal activation in LH. Rats underwent self-administration training for $4 \%(\mathrm{v} / \mathrm{v})$ alcoholic beer followed by extinction. AcbSh inactivation reinstated extinguished alcohol seeking when infusions were made after, but not before, extinction training. We then used immunohistochemical detection of c-Fos as a marker of neuronal activity, combined with immunohistochemical detection of the orexin and cocaine- and amphetamine-related transcript (CART) peptides, to study the profile and phenotype of neural activation during reinstatement produced by AcbSh inactivation. AcbSh inactivation increased c-Fos expression in hypothalamus, as well as in paraventricular thalamus and amygdala. Within hypothalamus, there was an increase in the number of orexin and CART cells expressing c-Fos. Finally, we hypothesized that concurrent inactivation of LH would prevent reinstatement produced by inactivation of AcbSh alone. Our results confirmed this. Together, these findings suggest that AcbSh mediates extinction of reward seeking by inhibiting hypothalamic neuropeptide neurons. Reversible inactivation of the AcbSh removes this influence, thereby releasing hypothalamus from AcbSh inhibition and enabling reinstatement of reward seeking. These ventral striatal-hypothalamic circuits for extinction overlap with those that mediate satiety, and we suggest that extinction training inhibits drug seeking because it co-opts neural circuits originally selected to produce satiety.

\section{Introduction}

Animals readily learn to self-administer drugs of abuse. In turn, self-administration can be reduced when the drugseeking behavior no longer yields a drug reward. This decline in drug seeking is described as extinction. Extinction does not erase the original learning that mediated previous drug seeking. Rather, it actively inhibits drug seeking. This inhibition can be removed in several ways, including via re-presentations of the reinforcer (reinstatement) (de Wit and Stewart, 1981), presentations of a drug-associated stimulus (cue-induced reinstatement) (de Wit and Stewart, 1981), or context change between extinction and test (context-induced reinstatement) (Crombag and Shaham, 2002). Despite increasing knowledge regarding neural mechanisms for reinstatement of drug seeking (e.g., Kalivas and Volkow, 2005; Crombag et al., 2008), much less is known about how extinction masks or inhibits drug seeking. Understanding the neural pathways that underlie extinction may provide insights into mechanisms that promote abstinence from drug seeking.

Received 0ct. 4, 2009; revised Jan. 31, 2010; accepted Feb. 16, 2010.

These experiments were supported by an Australian Postgraduate Award to E.Z.M. and by a project grant from the National Health and Medical Research Council to G.P.M. (510199). G.P.M. is an Australian Research Council QEII Fellow (DP0877430). We thank Wan Yee Macy Chan, Laura Bradfield, and Dr. Jean-Marie Maddux for their comments on this manuscript.

Correspondence should be addressed to Dr. Gavan P. McNally, School of Psychology, The University of New South Wales, Sydney, NSW, 2052, Australia. E-mail: g.mcnally@unsw.edu.au.

DOI:10.1523/JNEUROSCI.4933-09.2010

Copyright $\odot 2010$ the authors $\quad 0270-6474 / 10 / 304626-10 \$ 15.00 / 0$
Peters et al. (2008) identified nucleus accumbens shell (AcbSh) in inhibiting cocaine seeking after extinction training. These authors trained rats to lever press for intravenous infusions of cocaine and subsequently extinguished cocaine-seeking behavior. When cocaine seeking was sufficiently reduced, AcbSh was reversibly inactivated before test, resulting in the reinstatement of cocaineseeking behavior. This implicates AcbSh in the expression of extinction. However, the role of AcbSh in extinction of other drug and nondrug rewards, as well as the circuit level mechanisms for AcbSh contributions to extinction of drug seeking, are unclear.

Lateral hypothalamus $(\mathrm{LH})$ is a potential AcbSh target during extinction of reward seeking. Using retrograde neuronal tracer injected into LH combined with detection of c-Fos protein in the AcbSh, Marchant et al. (2009) show that AcbSh projection neurons to $\mathrm{LH}$ are activated during expression of extinction of alcoholic beer seeking. Functionally, LH mediates the behavioral impact of drug-associated stimuli (Harris et al., 2005, 2007) and contains the neuropeptides orexin and cocaine- and amphetaminerelated transcript (CART), which have key roles in appetitive motivation and reinstatement of drug seeking (Harris et al., 2005; Lawrence et al., 2006; Dayas et al., 2008; Richards et al., 2008). As AcbSh projection neurons terminate apposite to LH orexin neurons (Yoshida et al., 2006), AcbSh might contribute to extinction of drug and reward seeking by inhibiting orexin neurons in LH. Although there is evidence that AcbSh projections to $\mathrm{LH}$ are important for inhibiting feeding behavior (Stratford and Kelley, 1999; Stratford, 2005), the involvement of an AcbSh-LH pathway in extinction remains unknown. 
We studied the role of AcbSh and its interactions with LH in extinction of reward seeking. First, we reversibly inactivated AcbSh to confirm its role in extinction. We then used immunohistochemical detection of c-Fos as a marker of neuronal activity, combined with immunohistochemical detection of orexin and CART peptides, to study the profile and phenotype of neural activation during reinstatement produced by AcbSh inactivation. Finally, to investigate a causal role for AcbSh-LH interactions in extinction, we examined whether concurrent inactivation of LH would prevent reinstatement produced by AcbSh inactivation.

\section{Materials and Methods}

\section{Subjects}

Experimentally naive male Long-Evans rats (Monash Animal Services) weighing 310-330 g before surgery were housed in groups of eight and maintained on a 12/12 h light/dark cycle (lights on at 7:00 A.M.). Food and water were available ad libitum until $1 \mathrm{~d}$ before behavioral training, after which rats were allowed $1 \mathrm{~h}$ access to food and water following daily training sessions. All procedures were approved by the Animal Care and Ethics Committee at The University of New South Wales and conducted in accordance with the National Institute of Health (NIH) Guide for the Care and Use of Laboratory Rats (NIH Publications No. 80-23) revised 1996. The procedures were designed to minimize the number of animals used.

\section{Behavioral apparatus}

All self-administration, extinction training, and tests were conducted in eight standard Med Associates operant chambers, each enclosed in a sound- and light-attenuating cabinet equipped with a fan that provided constant ventilation and low-level background noise. For all chambers, front (hinged door) and rear walls were constructed of clear Perspex, and end walls were made of stainless steel. Inside each chamber, two nosepoke holes containing a white cue light were symmetrically located on one side wall of the chamber, $3 \mathrm{~cm}$ above a grid floor. A recessed magazine was located behind a $4 \times 4 \mathrm{~cm}$ opening in the center of the same wall between the two nosepokes. Responding on one (active) nosepoke delivered beer reward to the magazine, whereas responding on the other (inactive) nosepoke had no programmed consequences. There was no illumination in these chambers other than that provided by the white cue light recessed in the active nosepoke.

\section{Surgery}

Rats were injected intraperitoneally with the anesthetic ketamine (Ketapex; Apex Laboratories; concentration of $100 \mathrm{mg} / \mathrm{kg}$ ) and with $0.3 \mathrm{ml} / \mathrm{kg}$ muscle relaxant, xylazine (Rompun; Bayer; concentration of $20 \mathrm{mg} / \mathrm{ml}$ ). They were shaved and then placed in a stereotaxic frame (Model 900, Kopf) with the incisor bar maintained at $\sim 3.3 \mathrm{~mm}$ below horizontal to achieve a flat skull position. Rats were implanted bilaterally with 26 gauge guide cannulae (Plastics One). In experiment 1 , guide cannulae were aimed at either the dorsal or ventromedial AcbSh. Flat skull coordinates relative to bregma were $+1.35 \mathrm{~mm}$ anteroposterior (AP), $\pm 0.75 \mathrm{~mm}$ mediolateral (ML), and $-5.6 \mathrm{~mm}$ or $-6.5 \mathrm{~mm}$ dorsoventral (DV; AcbSh-D and AcbSh-V, respectively). In experiments 2 and 3, guide cannulae were aimed at the AcbSh-V using the above coordinates. In experiment 4, rats were implanted with guide cannulae in AcbSh-V as described above and also in the LH, bilaterally. Flat skull coordinates for $\mathrm{LH}$ relative to bregma were $-2.3 \mathrm{AP}, \pm 3.4 \mathrm{ML}$, and $-7.5 \mathrm{DV}$.

All guide cannulae were aimed $1 \mathrm{~mm}$ above target site, with coordinates based on the rat brain atlas of Paxinos and Watson (2005). Cannulae were secured to the skull using jeweler's screws and acrylic cement. Obturators with dust caps were fitted to the guide cannulae to prevent occlusion. Immediately after surgery, rats were injected subcutaneously with $5 \mathrm{mg} / \mathrm{kg}$ carprofen and intramuscularly with $0.3 \mathrm{ml}$ of procaine penicillin $(300 \mathrm{mg} / \mathrm{ml})$ and $0.1 \mathrm{ml}$ of cephazolin $(100 \mathrm{mg} / \mathrm{ml})$. Rats were given 5-7 d postoperative recovery before the start of behavioral procedures, during which time they were monitored and weighed daily.

\section{Microinfusion procedure}

For intracranial infusions, 33 gauge cannula injectors (which projected 1 $\mathrm{mm}$ ventral to the tip of the guide cannula) were connected to a $10 \mu \mathrm{l}$
Hamilton syringe via polyethylene-50 tubing, which was mounted onto an infusion pump (KD Scientific). Rats received infusions of saline or a solution containing both $\mathrm{GABA}_{\mathrm{B}}$ and $\mathrm{GABA}_{\mathrm{A}}$ agonists, baclofen (1.0 $\mathrm{mm}$ ) and muscimol hydrobromide $(0.1 \mathrm{~mm})$, respectively (B/M; SigmaAldrich). All microinjections were made in a volume of $0.5 \mu$ l per side over $2 \mathrm{~min}$. These volumes and doses have been used in previous studies to inactivate the AcbSh and LH separately from their adjacent brain regions (Floresco et al., 2008; Fuchs et al., 2008; Marchant et al., 2009). After allowing an additional 2 min for diffusion, microinjectors were removed and rats were returned to their home cage for $\sim 2 \mathrm{~min}$, before being tested in the self-administration chamber.

\section{Self-administration training and extinction}

Across experiments, self-administration and extinction sessions were identical. After postoperative recovery rats were run daily in squads of eight. On the first $2 \mathrm{~d}$, rats received $2 \times 20$ min magazine training sessions (per day) in the self-administration chamber. During these sessions rats received 10 noncontingent deliveries of $0.6 \mathrm{ml}$ of decarbonated beer (Coopers Birrell's Premium, $<0.5 \%$ w/v alcohol content) into the magazine cup at time intervals variable around a mean of $1.2 \mathrm{~min}$. Pure ethanol was added to the beer so that it resembled full strength beer (adjusted to $4 \% \mathrm{v} / \mathrm{v}$ alcohol). From days 3 to 9 , rats received daily $1 \mathrm{~h}$ self-administration sessions. During this phase, responses on the active nosepoke triggered a syringe pump, delivering $0.6 \mathrm{ml}$ of $4 \% \mathrm{v} / \mathrm{v}$ alcoholic beer into the magazine cup on an FR-1 schedule of reinforcement, and extinguished the white cue light recessed in the nosepoke during a $24 \mathrm{~s}$ timeout. All responses on the inactive nosepoke had no programmed consequences.

Following self-administration, rats were given daily $1 \mathrm{~h}$ extinction sessions for $4 \mathrm{~d}$, except where noted in experiment 2. Procedures for extinction were identical to self-administration, except that syringes were removed from infusion pumps so that responses on the active nosepoke no longer resulted in the delivery of beer.

Before each self-administration and extinction session, rats were adapted to the conditions of the intracranial infusion procedure: obturators were removed and the rats were placed into infusion buckets for 4 $\min$. The obturators were then reinserted and the rats were returned to their home cages for $\sim 2$ min before being placed into self-administration chambers.

Experiment 1: effects of AcbSh inactivation on expression of extinction. Following self-administration and extinction training, rats were tested under conditions identical to extinction. Immediately before test, rats received bilateral microinfusion of saline (SAL group) or baclofen + muscimol hydrobromide (B/M group) into the AcbSh-D or AcbSh-V. We included an AcbSh-D group to determine whether reinstatement effects were related to diffusion of the drug dorsally toward the lateral ventricle. Therefore, there were four groups (SAL AcbSh-D, SAL AcbSh-V, B/M AcbSh-D, and B/M AcbSh-V), each matched according to the number of active nosepokes made over the last day of selfadministration training and the first $2 \mathrm{~d}$ of extinction. Following test, rats received an additional day of extinction training (drug free, extinction day 5).

Experiment 2: effects of AcbSh inactivation on the acquisition of extinction. Rats were trained to self-administer beer. They then received 2 consecutive days of extinction training. Rats received microinfusion of saline or B/M into the AcbSh-V before the first day of extinction training. No infusions were given on the second day, which served as a test. Microinfusions were targeted at the ventromedial AcbSh, as this was found to be the most effective site for reinstating the previously extinguished response (shown in Results). Groups were matched on the average number of active nosepokes made over the last day of self-administration.

Experiment 3: $c$-Fos induction in orexin and CART neurons associated with reinstatement produced by AcbSh inactivation. Responding was trained and then extinguished (as in experiment 1). Immediately before test under extinction conditions, rats received bilateral microinfusion of saline or B/M into the ventromedial AcbSh, with groups matched as in experiment 1 . Time of testing (i.e., morning, afternoon) was counterbalanced between groups as orexin neurons in the medial and perifornical hypothalamic regions show diurnal variation in c-Fos expression 
(Estabrooke et al., 2001). At the conclusion of testing, rats were returned to their home cage for 60 min until perfusion.

Experiment 4: role of LH in reinstatement produced by AcbSh inactivation. We investigated whether reinstatement of reward seeking elicited by infusions of B/M into the AcbSh was dependent on the LH. Rats received self-administration training followed by extinction. Subsequently, all rats were tested under extinction conditions. Immediately before test, rats were infused with saline or B/M into the ventromedial AcbSh and simultaneously infused with either saline or B/M into the LH. All infusions were bilateral. Thus, there were four groups, SAL-SAL, SAL-BM, $\mathrm{BM}-\mathrm{SAL}$, and BM-BM, labeled according to the type of infusion given in AcbSh and LH, respectively. All groups were matched as in experiment 1.

\section{Histology and immunohistochemistry}

For experiments 1,2, and 4, rats were given an overdose of sodium pentobarbital $(100 \mathrm{mg} / \mathrm{kg}$, i.p.) at the conclusion of the study. Brains were extracted, frozen, and sectioned coronally at $40 \mu \mathrm{m}$ using a cryostat (Microm 560). All sections containing cannula tracts were collected onto glass slides, stained for Nissl substance with cresyl violet, and coverslipped with the mounting agent Entellan. Sections were examined under light microscope to determine cannula tip placements, which were then mapped onto plate sections from the atlas of Paxinos and Watson (2005).

Rats in the immunohistochemistry study (experiment 3 ) were deeply anesthetized with sodium pentobarbital ( $100 \mathrm{mg} / \mathrm{kg}$, i.p.) at $2 \mathrm{~h}$ from the start of testing and perfused transcardially with $50 \mathrm{ml}$ of $0.9 \%$ saline, containing heparin $(5000 \mathrm{IU} / \mathrm{ml})$, followed by $400 \mathrm{ml}$ of $4 \%$ paraformaldehyde in $0.1 \mathrm{~m}$ phosphate buffer (PB), $\mathrm{pH}$ 7.4. Brains were postfixed for $1 \mathrm{~h}$ in the same fixative and placed in $20 \%$ sucrose solution over 2 nights. Subsequently, brains were blocked using a matrix aligned to the atlas of Paxinos and Watson (2005) and $40 \mu \mathrm{m}$ coronal sections were cut using a cryostat (Microm 560). Four serially adjacent sets of LH sections and two serially adjacent sets of AcbSh sections were obtained from each brain and stored in $0.1 \%$ sodium azide in $0.1 \mathrm{M} \mathrm{PBS,} \mathrm{pH} \mathrm{7.2.} \mathrm{To} \mathrm{determine}$ placement of the cannula tip and excessive damage, one series of sections through the AcbSh was selected from each rat and stained for Nissl substance as described above.

To reveal c-Fos immunoreactivity (-IR) in combination with orexinor CART-IR, two separate series of hypothalamic sections were processed using two-color peroxidase immunohistochemistry. Sections were washed in $0.1 \mathrm{M} \mathrm{PB}$, followed by $50 \%$ ethanol, $50 \%$ ethanol with $3 \%$ $\mathrm{H}_{2} \mathrm{O}_{2}$, then 5\% normal horse serum (NHS) in PB (30 min each). Sections were then incubated in goat antiserum against c-Fos [1:1000; c-Fos (4), sc-52, Santa Cruz-Biotechnology] and rabbit antiserum against orexin-A (1:20,000; Santa Cruz Biotechnology) or rabbit antiserum against CART 55-102 (1:20,000; Phoenix Pharmaceuticals), in a PB solution containing $2 \%$ NHS and $0.2 \%$ Triton X-10 $\left(48 \mathrm{~h}\right.$ at $\left.4^{\circ} \mathrm{C}\right)$. The sections were then washed and incubated in biotinylated donkey anti-sheep IgG for c-Fos (1:1000; Jackson ImmunoResearch Laboratories, $24 \mathrm{~h}$ at $\left.4^{\circ} \mathrm{C}\right)$. Finally, the sections were incubated in $\mathrm{ABC}$ reagent (Vector Elite kit: $6 \mu \mathrm{l} / \mathrm{ml}$ avidin and $6 \mu \mathrm{l} / \mathrm{ml}$ biotin; Vector Laboratories, $2 \mathrm{~h}$ at room temperature), washed in Tris buffer, $\mathrm{pH}$ 7.6, and then incubated (15 min) in a nickel-intensified diaminobenzidine solution (DAB) containing $0.1 \%$ 3,3-diaminobenzidine, $0.8 \%$ D-glucose, $0.016 \%$ ammonium chloride, and $0.032 \%$ nickel sulfate to reveal c-Fos-IR as a black immunoreactive nuclei after the addition of $0.2 \mu \mathrm{l} / \mathrm{ml}$ glucose oxidase $(24 \mathrm{mg} / \mathrm{ml}, 307$ $\mathrm{U} / \mathrm{mg}$, Sigma-Aldrich). Brain sections were then washed in Tris/PB and reincubated in biotinylated donkey anti-rabbit for orexin or CART (1: 1000; Jackson ImmunoResearch Laboratories). The DAB reaction was repeated without nickel intensification to localize orexin- or CART-IR, revealed as a brown reaction product. Sections were mounted onto gelatin-coated slides, dehydrated, cleared in histolene, and coverslipped with Entellan.

\section{Neuronal counting}

The hypothalamus was divided into three regions based on structural landmarks (Paxinos and Watson, 2005). The dorsomedial (DMH) region was formed by the area between the third ventricle and the medial edge of the mammillothalamic tract; the perifornical $(\mathrm{PeF})$ extended from the DMH boundary to beyond the lateral edge of the fornix (ap- proximately half the fornix width past the fornix, laterally); and the $\mathrm{LH}$ included the remaining area extending to the medial edge of the internal capsule. Total c-Fos-positive and dual-labeled orexin/c-Fos-positive nuclei in each hypothalamic region were counted by two observers unaware of group allocations, with inter-rater reliability of 0.9. Dual-labeled CART/c-Fos-positive nuclei were counted by an observer unaware of group allocations. Unilaterally matched coronal sections including the hypothalamus, amygdala, paraventricular thalamus, and arcuate nucleus were counted at six different levels, beginning at approximately -2.52 $\mathrm{mm}$ from bregma (Paxinos and Watson, 2005). All sections counted were $\sim 160 \mu \mathrm{m}$ apart.

\section{Data analyses}

For behavioral data, the mean numbers of active and inactive responses were analyzed using mixed group $\times$ response $\times$ day factor ANOVA with orthogonal contrasts. For immunohistochemical data, mean total counts of labeled neurons were analyzed using ANOVA and also correlated with active responding on test using the Pearson correlation coefficient. In experiments 1 and 4, mean latency to make initial active response was also analyzed. For all analyses, type I error rate $(\alpha)$ was controlled at 0.05 .

\section{Results}

\section{Experiment 1: effects of AcbSh inactivation on expression of extinction}

To examine the role of AcbSh in expression of extinction of reward seeking, rats were trained and extinguished. Immediately before test, rats received infusions of saline or $G_{A B A}$ and $\mathrm{GABA}_{\mathrm{A}}$ agonists, baclofen and muscimol (B/M), into either dorsal or ventromedial AcbSh.

\section{Histology}

Bilateral placement of injection tips are indicated in Figure $1 A$. Seven rats were excluded from analyses due to misplaced cannulae. Final group sizes were as follows: SAL AcbSh-D, $n=7$; SAL AcbSh-V, $n=8 ; \mathrm{B} / \mathrm{M}$ AcbSh-D, $n=7$; and B/M AcbSh-V, $n=10$.

\section{Behavior}

All rats acquired high levels of responding during training. On the last day of acquisition training, the mean \pm SEM numbers of active and inactive nosepokes were $122.44 \pm 12.11$ and $4.03 \pm$ 0.49 , respectively. Between groups there were no overall differences in responding on the last day of training (main effect and interaction: $F_{(1,28)}$ values $<1, p$ values $\left.>0.05\right)$; all rats made significantly more active than inactive nosepokes $\left(F_{(1,28)}=182.57\right.$, $p<0.001)$.

Mean \pm SEM responses during extinction training are shown in Figure $1 C$ (left). During extinction training, there were no significant differences between groups (main effects and interactions: $F_{(1,28)}$ values $<1.29$, $p$ values $\left.>0.05\right)$. All rats made significantly more active than inactive nosepokes, averaged across days of extinction $\left(F_{(1,28)}=150.03, p<0.001\right)$. Overall, responding significantly decreased across days of extinction $\left(F_{(1,28)}=126.92\right.$, $p<0.001)$, and this decrease was greater on the active than on the inactive nosepoke $\left(F_{(1,28)}=133.84, p<0.001\right)$.

Figure $1 C$ (right) shows the mean \pm SEM number of responses on test. Testing conditions were identical to extinction training. Overall, group B/M AcbSh-V responded significantly more than all other groups $\left(F_{(1,28)}=29.25, p<0.001\right)$, and this difference was greater on the active than on the inactive nosepoke $\left(F_{(1,28)}=10.03\right.$, $p<0.001)$. There were no significant differences between the other groups, SAL AcbSh-D, SAL AcbSh-V, or B/M AcbSh-D $\left(F_{(1,28)}\right.$ values $<1, p$ values $\geq 0.05$ ). The latency in minutes to first active response following placement in the chamber was also analyzed for AcbSh-V groups. There was no difference in latency to first response between group SAL AcbSh-V (mean = 4.54; SEM = 2.98) and group B/M AcbSh-V $($ mean $=5.46 ;$ SEM $=4.73)$. 
A

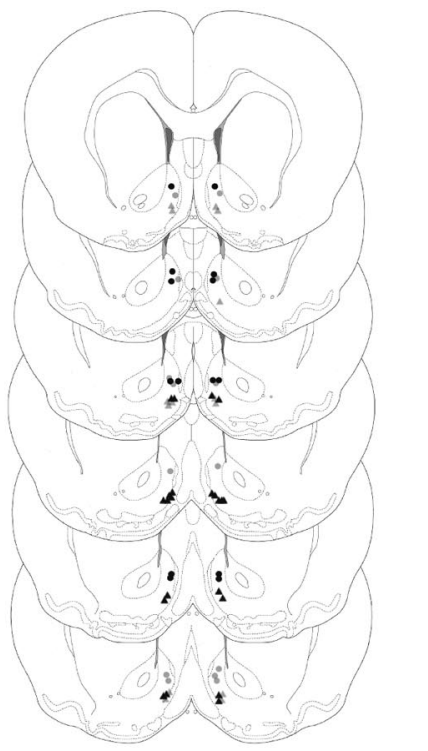

C

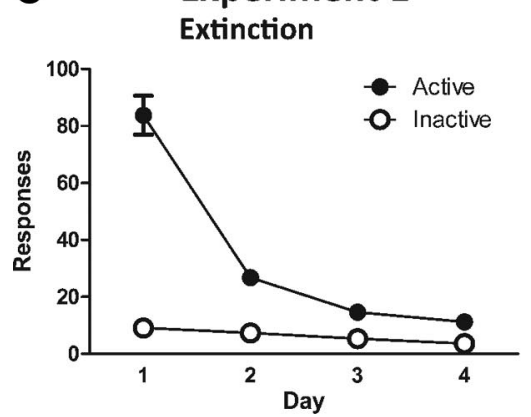

D

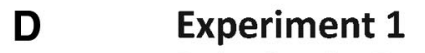
Extinction day 5

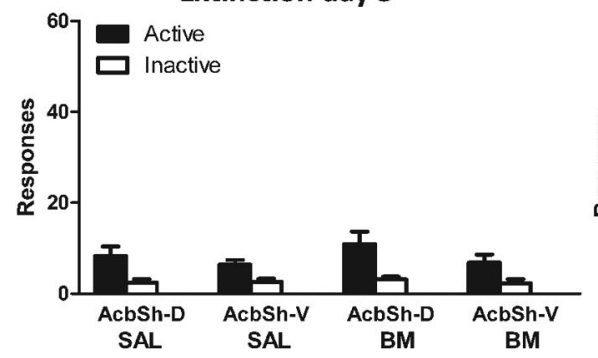

$+2.04 \mathrm{~mm}$

$+1.80 \mathrm{~mm}$

$+1.56 \mathrm{~mm}$

$+1.28 \mathrm{~mm}$

$+1.20 \mathrm{~mm}$

$+1.08 \mathrm{~mm}$

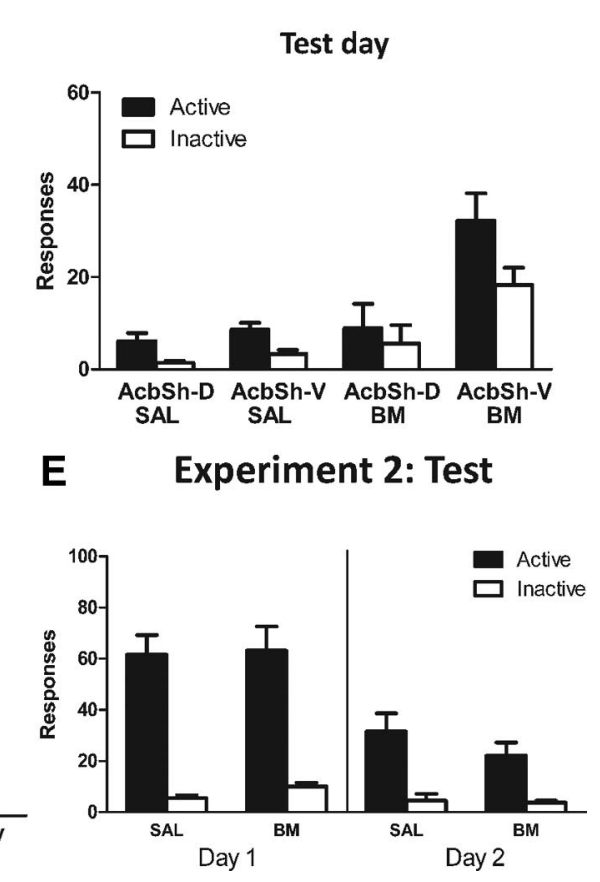

Figure 1. Microinfusion cannula placements for experiments 1 and 2 as verified on Nissl-stained sections. A, Experiment 1 groups: SAL AcbSh-D (gray dots), SAL AcbSh-V (gray triangles), B/M AcbSh-D (black dots), and B/M AcbSh-V (black triangles). In this and remaining figures, symbols represent the most ventral point of the cannula track, indicated on coronal sections adapted from Paxinos and Watson (2005). B, Experiment 2 groups: SAL (gray dots) and B/M (black dots). C, Experiment 1: mean \pm SEM numbers of active and inactive nosepokes during extinction (left) and test (right). Before test, rats received infusions of $B / M$ or saline. $\boldsymbol{D}$, Experiment 1 : mean \pm SEM numbers of active and inactive nosepokes during extinction day 5 . $\boldsymbol{E}$, Experiment 2: mean \pm SEM numbers of active and inactive nosepokes during test (extinction days 1 and 2 ). Rats received infusions of $B / M$ or saline into ventromedial AcbSh immediately before test (extinction day 1 ) and not on extinction day 2.

On the following day (extinction day 5) (Fig. 1D), there were no significant differences between groups $\left(F_{(1,28)}\right.$ values $<2.51, p$ values $\geq 0.05)$. This suggests that the effect of AcbSh inactivation on expression of extinction was specific to the presence of $\mathrm{B} / \mathrm{M}$ infused into the AcbSh-V.

Experiment 2: effects of AcbSh inactivation on the acquisition of extinction

Experiment 1 showed that reversible inactivation of AcbSh-V but not AcbSh-D prevented the expression of extinction of reward seeking, and so reinstated responding. Experiment 2 studied the effects of AcbSh-V inactivation on the acquisition of extinction learning. Immediately before the first day of extinction training, rats were infused with either $\mathrm{B} / \mathrm{M}$ or saline into AcbSh-V. Rats were tested again (drug free) under extinction conditions on the following day.

\section{Histology}

Bilateral placements of injection tips are indicated in Figure $1 B$. Five rats were excluded from analyses due to misplaced cannulae. Final group sizes were as follows: SAL, $n=7$; and $\mathrm{B} / \mathrm{M}, n=9$.

\section{Behavior}

All rats acquired high levels of responding during training. On the last day of acquisition training, the mean \pm SEM numbers of active and inactive nosepokes were $86.69 \pm 9.22$ and $3.81 \pm 1.02$, respectively. Between groups, there were no overall differences in responding on the last day of training (main effect and interaction: $F_{(1,14)}$ values $<1, p$ values $\left.>0.05\right)$; all rats made significantly more active than inactive nosepokes $\left(F_{(1,14)}=88.71\right.$, $p<0.001$ ).

Mean \pm SEM responses during the first $2 \mathrm{~d}$ of extinction are shown in Figure $1 E$. There were no significant differences between groups across days or on response type $\left(F_{(1,14)}\right.$ values $<1.52$, $p$ values $>0.05$ ). All rats made significantly more active than inactive nosepokes, averaged across days $\left(F_{(1,14)}=102.41, p<0.001\right)$. Overall, responding significantly decreased on the second day of extinction $\left(F_{(1,14)}=34.47, p<0.001\right)$, and this decrease was greater on the active than on the inactive nosepoke $\left(F_{(1,14)}=40.88, p<\right.$ $0.001)$. These results show that AcbSh inactivation has no significant effect on the acquisition of extinction.

\section{Experiment 3: c-Fos induction in hypothalamic orexin and CART neurons associated with reinstatement following AcbSh inactivation}

The results of experiments 1 and 2 confirm and extend the recent findings of $\mathrm{Pe}$ ters et al. (2008) from cocaine seeking: reversible inactivation of the AcbSh prevents the expression but not acquisition of extinction of alcoholic beer seeking. This experiment used induction of the c-Fos protein during reinstatement produced by AcbSh inactivation to provide a neuroanatomical assessment of the possibility that an AcbSh-hypothalamic interaction may be critical for the expression of extinction of reward seeking. We studied the induction of c-Fos in the $\mathrm{DMH}, \mathrm{PeF}$, and $\mathrm{LH}$, and also the peptidergic phenotype (orexin and CART) of activated hypothalamic neurons. To assess 
the potential circuit-level mechanisms that might mediate reinstatement following AcbSh inactivation, we also studied c-Fos induction in CART neurons in the arcuate nucleus and central nucleus of the amygdala (CeA), as well as c-Fos induction in neurons within basolateral nucleus of the amygdala (BLA) and paraventricular thalamus (PVT).

\section{Histology}

Bilateral placement of injection tips are indicated in Figure $2 \mathrm{~A}$. Two rats were excluded from analyses; cannula tips for these rats were unverifiable due to excessive tearing of tissue along the cannula track. Final group sizes were as follows: SAL, $n=8$; and $\mathrm{B} / \mathrm{M}, n=6$.

\section{Behavior}

All rats acquired high levels of responding during training. On the last day of acquisition training, the mean \pm SEM numbers of active and inactive nosepokes were $104.64 \pm 9.44$ and $2.64 \pm 0.73$, respectively. Between groups, there were no overall differences in responding on the last day of training (main effect and interaction: $F_{(1,12)}$ values $<2.36, p$ values $>0.05)$; all rats made significantly more active than inactive responses $\left(F_{(1,12)}=141.14, p<0.001\right)$.

Mean \pm SEM responses during extinction training are shown in Figure $2 B$. During extinction training, there were no significant differences between groups (main effect and interactions: $F_{(1,12)}$ values $<1, p$ values $\left.>0.05\right)$. All rats made significantly more active than inactive nosepokes, averaged across days of extinction $\left(F_{(1,12)}=98.31, p<0.001\right)$. Overall, responding significantly decreased across days of extinction $\left(F_{(1,12)}=73.05, p<\right.$ $0.001)$, and this decrease was greater on the active than on the inactive nosepoke $\left(F_{(1,12)}=64.69, p<0.001\right)$.

Figure $2 C$ shows the mean \pm SEM number of responses following infusions of either saline or B/M into AcbSh. Testing conditions were identical to extinction training. Overall, rats receiving $\mathrm{B} / \mathrm{M}$ responded significantly more than those receiving saline $\left(F_{(1,12)}=38.86, p<0.001\right)$. Importantly, this difference between groups was significantly greater for active than for inactive nosepokes (group $\times$ response interaction: $F_{(1,12)}=16.59$, $p<0.002$ ). These results confirm that reversible inactivation of AcbSh-V reinstates extinguished responding.

\section{Immunohistochemistry}

Table 1 shows the mean \pm SEM total c-Fos-IR, orexin-IR, and CART-IR for each group in all brain regions examined. Table 2 shows the mean \pm SEM number of cells expressing dual-IR for cFos/orexin, c-Fos/CART, percentage of orexin neurons expressing c-Fos-IR, and percentage of CART neurons expressing c-Fos-IR.

\section{Hypothalamus}

Figure $3 A$ shows a photomicrograph of a representative coronal section through the hypothalamus indicating approximate boundaries used for cell counts. Figure $3, B$ and $C$, shows photomicrographs of representative dual-labeled cells expressing c-Fos/orexin-IR and c-Fos/CART-IR, respectively.

$c$-Fos-IR. Figure $3 D$ shows the mean \pm SEM total counts for c-Fos-IR in hypothalamus. The mean number of cells

\section{Experiment 3}
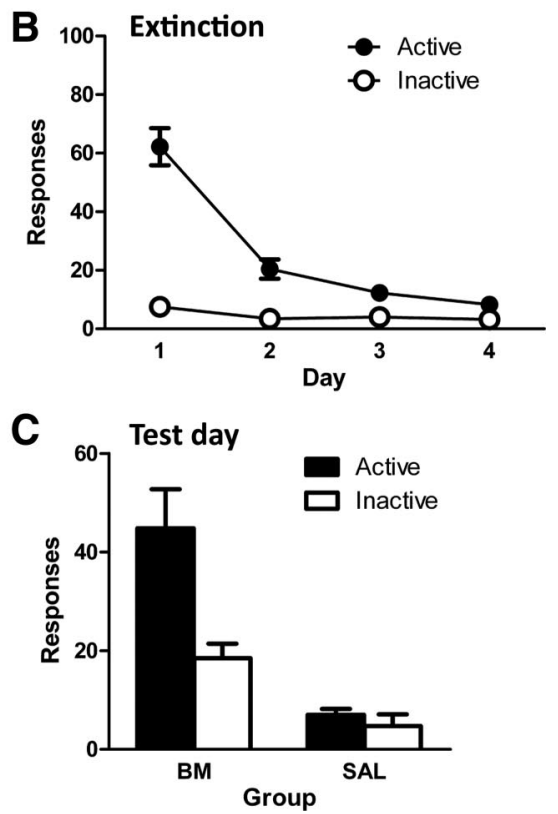
Table 1. Mean (SEM) counts of total c-Fos-IR, orexin-IR, and CART-IR

\begin{tabular}{|c|c|c|c|c|c|c|}
\hline & \multicolumn{2}{|l|}{ c-Fos } & \multicolumn{2}{|l|}{ Orexin } & \multicolumn{2}{|l|}{ CART } \\
\hline & SAL & $\mathrm{BM}$ & SAL & $\mathrm{BM}$ & SAL & BM \\
\hline DMH & $591.5(33.6)$ & 1135.5 (101.9) & $62.9(5.5)$ & $66.8(7.2)$ & $173.4(9.4)$ & $163.8(19.8)$ \\
\hline PeF & 855.1 (37.1) & 2112.7 (101.6) & 394 (19.4) & $414(26.2)$ & $308.3(19.7)$ & $313.3(20.1)$ \\
\hline $\mathrm{LH}$ & $291.6(36.7)$ & 931.7 (78.3) & 154 (7.6) & $171(13)$ & $173.1(16.8)$ & $167.3(9.6)$ \\
\hline CeA & $38.8(5.5)$ & 81.5 (19.7) & - & - & $93.6(5.2)$ & $89.5(6.9)$ \\
\hline LA/BLA & 200.8 (23.7) & $360(29.8)$ & - & - & - & - \\
\hline PVT & $126.9(9.8)$ & $213(21.7)$ & - & - & - & - \\
\hline Arcuate nucleus & $22.3(1.0)$ & $207.8(34.7)$ & - & - & $92.9(5.6)$ & $86.8(7.3)$ \\
\hline
\end{tabular}

Table 2. Mean (SEM) counts and percentages of dual orexin/c-Fos-IR and CART/c-Fos-IR cells

\begin{tabular}{|c|c|c|c|c|c|c|c|c|}
\hline & Orexin/c-Fos & & Orexin/c-F & & CART/c-Fos & & CART/C-F & \\
\hline & $\overline{\mathrm{SAL}}$ & BM & $\overline{\mathrm{SAL}}$ & BM & $\overline{\mathrm{SAL}}$ & BM & $\overline{\mathrm{SAL}}$ & BM \\
\hline DMH & $38.8(5.5)$ & $51.7(7.2)$ & $60.0(5.2)$ & $76.3(3.5)$ & $12.9(2.1)$ & $14(4.0)$ & $7.3(1.0)$ & $8.1(1.6)$ \\
\hline PeF & $175.5(17.6)$ & $285.5(9.3)$ & $44.9(4.5)$ & $69.7(2.9)$ & $5.4(1.5)$ & $10.8(1.1)$ & $1.7(0.5)$ & $3.5(0.3)$ \\
\hline LH & $18.9(2.8)$ & $61(12.7)$ & $12.6(2.0)$ & $35.1(5.5)$ & $2(0.5)$ & $3.7(1.1)$ & $1.1(0.3)$ & $2.1(0.6)$ \\
\hline CeA & - & - & - & - & $6.9(2.2)$ & $15.5(4.1)$ & $7.0(2.1)$ & $16.8(3.9)$ \\
\hline Arcuate nucleus & - & - & - & - & $7.4(1.4)$ & $3.8(0.8)$ & $7.6(1.2)$ & $4.0(1.0)$ \\
\hline
\end{tabular}

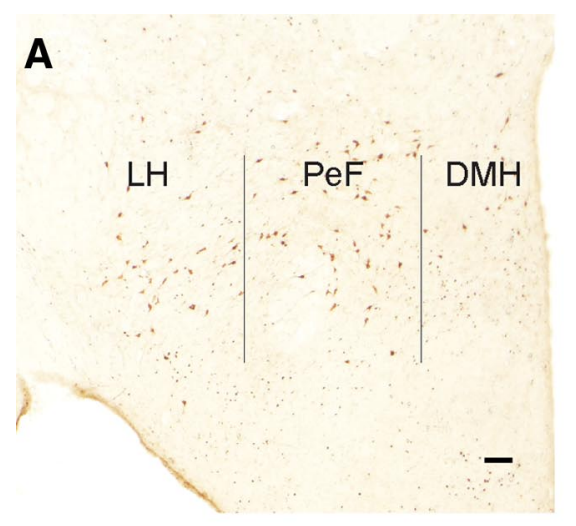

D

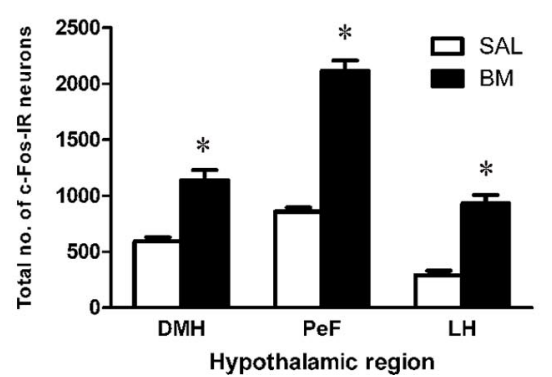

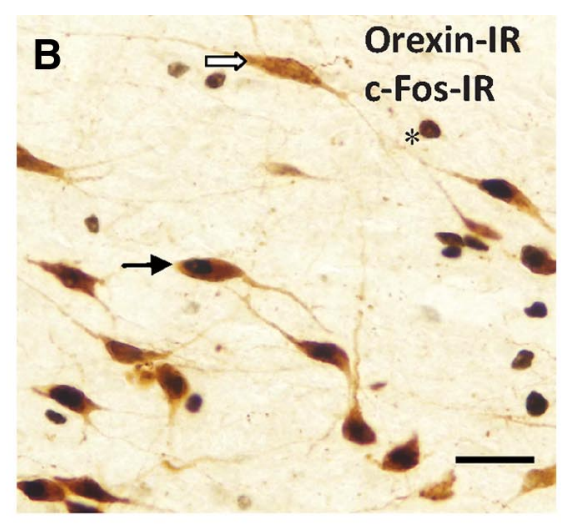

E

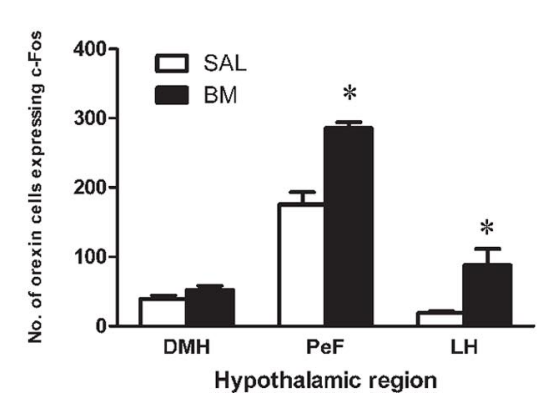

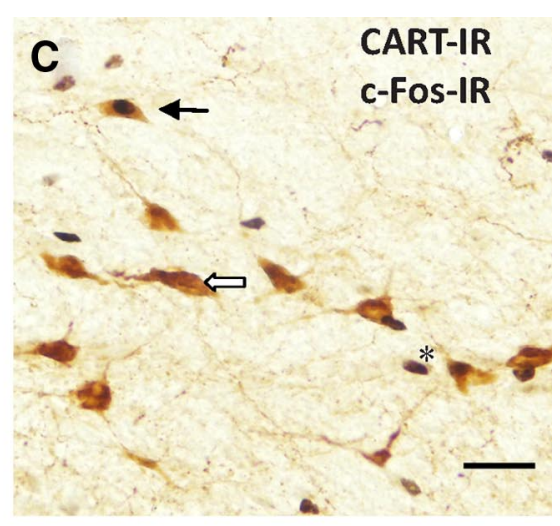

F

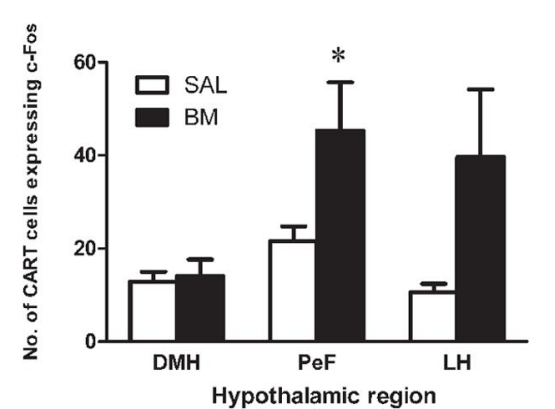

Figure 3. Dual-labeled c-Fos/orexin-IR and c-Fos/CART-IR cells were found in distinct regions of the hypothalamus. $\boldsymbol{A}$, Photomicrograph of a representative coronal section through the hypothalamus indicating approximate boundaries used for cell counts. B, C, Photomicrographs of representative dual-labeled c-Fos/orexin-IR or c-Fos/CART-IR (black arrow), single-labeled orexinor CART-IR (white arrow), and single-labeled Fos-IR (asterisk). D, Mean \pm SEM number of total c-Fos-IR in each hypothalamic region. c-Fos-IR was significantly increased in all regions of the hypothalamus following B/M infusions into AcbSh. $\boldsymbol{E}, \boldsymbol{F}$, Mean \pm SEM number of dual-labeled c-Fos/orexin-IR and c-Fos/CART-IR in each hypothalamic region. Following AcbSh infusions of B/M, dual-labeled c-Fos/orexin-IR cells increased significantly in PeF and LH while c-Fos/CART-IR increased significantly in PeF. ${ }^{*} p<0.05$. Scale bars: $\boldsymbol{A}, \boldsymbol{B}, 100 \mu \mathrm{m} ; \boldsymbol{C}, 200 \mu \mathrm{m}$.

4, $D$ and $E$, depicts representative dual-labeled cells in CeA and arcuate nucleus, respectively, while Figure $4 F$ depicts representative c-Fos-IR in PVT.

$c$-Fos-IR. Figure $4 G$ shows the mean \pm SEM number of cells expressing c-Fos-IR in amygdala, PVT, and arcuate nucleus. The mean number of c-Fos-IR was higher in group $\mathrm{B} / \mathrm{M}$ than in group SAL in the BLA $\left(F_{(1,12)}=21.01, p<0.001\right)$, $\operatorname{CeA}\left(F_{(1,12)}=6.73\right.$, $p<0.05), \operatorname{PVT}\left(F_{(1,12)}=18.54, p<0.001\right)$, and arcuate nucleus $\left(F_{(1,12)}=46.9, p<0.001\right)$.
CART-IR in CeA and arcuate nucleus. Figure $4 H$ shows the mean \pm SEM number of dual-labeled CART cells in CeA and arcuate nucleus. In CeA, the mean number of cells expressing both CART-IR and c-Fos-IR was higher in group B/M than in group SAL $\left(F_{(1,12)}=4.74, p<0.05\right)$. Analyses based on percentages of total CeA CART cells expressing c-Fos revealed similar differences between groups $\left(F_{(1,12)}=6.65, p<0.05\right)$. In the arcuate nucleus, the mean number of cells expressing both CART-IR and c-Fos-IR was higher in group SAL than in group 
$\mathrm{B} / \mathrm{M}\left(F_{(1,12)}=4.84, p<0.05\right)$. Analyses based on percentage of total CART cells expressing c-Fos-IR approached but did not reach significance $\left(F_{(1,12)}=4.44, p=\right.$ $0.057)$. There were no significant differences between groups in the total number of CART cells counted in the CeA and arcuate nucleus $\left(F_{(1,12)}\right.$ values $<1, p$ values $>0.05$ ).

Correlations for c-Fos-IR and duallabeled neurons with alcohol seeking. Active nosepokes on test correlated positively with single c-Fos-IR and percentage of orexin cells labeled with c-Fos-IR across the hypothalamus region, and separately in $\mathrm{LH}, \mathrm{PeF}$, and DMH ( $r$ values $>0.567, p$ values $\leq 0.05$ two tailed). c-Fos-IR also correlated positively with active nosepokes on test in arcuate nucleus and PVT, across amygdala, and separately in CeA and BLA ( $r$ values $>0.693, p$ values $<0.05$ two tailed). Percentage of CART cells dual labeled with c-Fos-IR correlated positively with active nosepokes on test in $\mathrm{PeF}$ ( $r=0.608, p<0.05$ two tailed $)$ and CeA ( $r=0.668, p<0.01$ two tailed); negatively in arcuate nucleus $(r=-0.618, p<0.05$ two tailed); but not in LH or DMH ( $r$ values $<0.179, p$ values $>0.05$ two tailed).

\section{Experiment 4: role of lateral hypothalamus in reinstatement following AcbSh inactivation}

In the previous experiments, reversible inactivation of the AcbSh reinstated extinguished responding and also increased c-Fos induction in hypothalamus. Given that the AcbSh projects preferentially to LH compared to DMH and PeF (Sano and Yokoi, 2007; Marchant et al., 2009), and that an AcbSh-LH pathway is activated during expression of extinction of reward seeking (Marchant et al., 2009), we investigated the causal role of LH in mediating reinstatement produced by AcbSh inactivation. To this end, rats were implanted with bilateral cannulae in both the AcbSh-V and LH. Rats were then trained and extinguished. Before test under extinction conditions, rats received infusions of saline or B/M into AcbSh, concurrent with infusion of saline or $\mathrm{B} / \mathrm{M}$ into LH. Thus, there were four groups, SAL-SAL, SAL-BM, BM-SAL, and BM-BM, labeled according to the type of infusion given in AcbSh and $\mathrm{LH}$, respectively.

\section{Histology}

Bilateral placement of injection tips are indicated in Figure $5 \mathrm{~A}$. Twelve rats were excluded from analyses due to misplaced cannulae and tissue damage. Final group sizes were as follows: SALSAL, $n=6 ; \mathrm{B} / \mathrm{M}-\mathrm{SAL}, n=8 ; \mathrm{SAL}-\mathrm{B} / \mathrm{M}, n=6$; and $\mathrm{B} / \mathrm{M}-\mathrm{B} / \mathrm{M}$, $n=6$.

\section{Behavior}

All rats acquired high levels of responding during training. On the last day of acquisition training, the mean \pm SEM numbers of active and inactive nosepokes were $96.77 \pm 12.15$ and $3.15 \pm$ 0.56 , respectively. Between groups there were no overall differ- ences in responding on the last day of training (main effects and interactions: $F_{(1,11)}$ values $<2.75, p$ values $\left.>0.05\right)$; all rats made significantly more active than inactive nosepokes $\left(F_{(1,22)}=60.23\right.$, $p<0.001)$.

Mean \pm SEM responses during extinction training are shown in Figure $5 B$. Across extinction training, there were no significant differences between groups (main effects and interactions: $F_{(1,22)}$ values $<1.55$, $p$ values $>0.05$ ). All rats made significantly more active than inactive nosepokes, averaged across days of extinction $\left(F_{(1,22)}=119.67, p<0.001\right)$. Overall, responding significantly decreased across days of extinction $\left(F_{(1,22)}=85.05, p<0.001\right)$, and this decrease was greater on the active than on the inactive nosepoke $\left(F_{(1,22)}=82.86, p<0.001\right)$.

Figure $5 C$ shows the mean \pm SEM number of active and inactive responses on test following bilateral infusions of saline or $\mathrm{B} / \mathrm{M}$ into AcbSh concurrent with bilateral infusions of saline or $\mathrm{B} / \mathrm{M}$ into $\mathrm{LH}$. Testing conditions were identical to extinction training. Overall, group B/M-SAL responded significantly more than all other groups $\left(F_{(1,22)}=13.97, p<0.001\right)$ and this increase was greatest on the active relative to inactive nosepoke $\left(F_{(1,22)}=\right.$ $10.72, p<0.01$ ). To explore whether $\mathrm{B} / \mathrm{M}$ infusions into $\mathrm{LH}$ independently suppressed responding, we compared group SALSAL with group SAL-BM and also compared group SAL-SAL with group BM-BM. These contrasts were not significant (main 


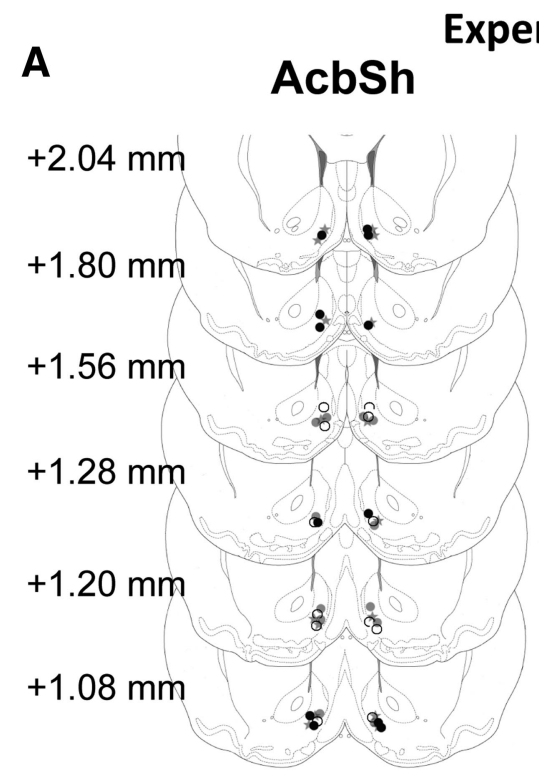

B
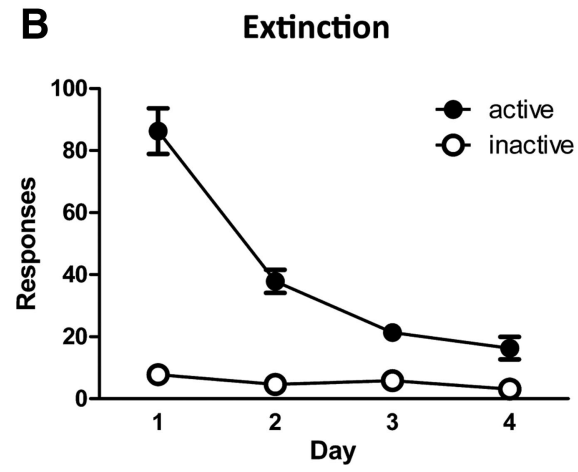

C
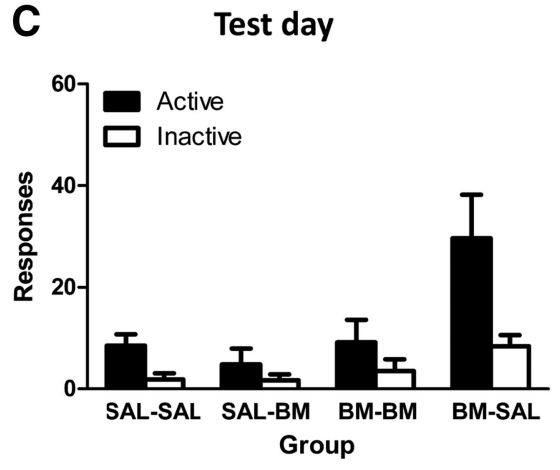

Figure 5. A, AcbSh and LH microinfusion cannula placements for experiment 4 as verified on Niss-stained sections. All rats were infused with saline or B/M into AcbSh and concurrently with saline or B/M into LH. There were four groups: SAL-SAL (open circles), BM-BM (black circles), SAL-BM (gray circles), and BM-SAL (gray stars); each group is labeled according to treatment received in AcbSh and $\mathrm{LH}$, respectively. $\boldsymbol{B}$, Mean \pm SEM number of active and inactive nosepokes during extinction. $\boldsymbol{C}$, Mean \pm SEM numbers of active and inactive nosepokes during test.

effects and interactions: $F_{(1,22)}$ values $<1, p$ values $\left.>0.05\right)$. To further explore effects of $\mathrm{B} / \mathrm{M}$ into either AcbSh or $\mathrm{LH}$, we also examined latency to make first active response. There were no significant differences between groups in latency to first active nosepoke after placement in the chamber $\left(F_{(1,22)}\right.$ values $<1.19, p$ values $>0.05)$. Together, these results show that concurrent inactivation of LH prevents reinstatement produced by inactivation of AcbSh.

\section{Discussion}

We provide evidence that AcbSh mediates extinction of alcoholic beer seeking through actions on hypothalamus. First, AcbSh inactivation reinstated extinguished alcoholic beer seeking. Second, this reinstatement was associated with c-Fos expression in hypothalamus, including in orexin and CART neurons. Finally, concurrent inactivation of LH blocked reinstatement produced by AcbSh inactivation. Together, these findings suggest that AcbSh mediates extinction by inhibiting hypothalamic neuropeptide neurons. Reversible AcbSh inactivation removes this influence, releasing hypothalamus from AcbSh inhibition and enabling reinstatement.

\section{The accumbens shell mediates extinction expression}

Bilateral AcbSh inactivation reinstated extinguished responding. This confirms previous findings using cocaine seeking (Peters et al., 2008) and shows that AcbSh mediates expression of extinguished reward seeking across different reinforcers. Thus, there might be common neural mechanisms for this extinction. Furthermore, this was anatomically specific to ventral AcbSh because reinstatement was not observed after $\mathrm{B} / \mathrm{M}$ infusions into dorsal AcbSh. This neuroanatomical specificity might suggest that neurons in ventromedial AcbSh are especially important for extinction of reward seeking.

Marchant et al. (2009) reported that dorsal AcbSh projection neurons to $\mathrm{LH}$ were associated with expression of extinction, whereas ventral projection neurons were associated with reinstatement of alcohol seeking. This contrasts with the present finding that inactivation of ventral, but not dorsal, AcbSh prevented extinction expression. This difference between infusions into ventral and dorsal AcbSh is also surprising given that some diffusion of $\mathrm{B} / \mathrm{M}$ infusion is expected. However, Marchant et al. (2009) used different contexts to assess extinction and reinstatement, whereas we tested for extinction and reinstatement in the same context. Thus, in Marchant et al. (2009) the context during reinstatement test was only associated with reinforcement, whereas here the test context was associated with both reinforcement and extinction. The function of AcbSh-V may differ depending on the associative history of the test context. Regardless, our findings support the conclusion that an AcbSh-LH pathway is important for extinction. Finally, consistent with Peters et al. (2008), we showed that inactivation of AcbSh immediately before initial extinction training has no effect on responding. This supports the behavioral specificity of infusions and shows that there are dissociable neural circuits for extinction acquisition and expression.

Although bilateral inactivation of AcbSh increases locomotor activity and reinstates responding, there are several reasons why it is unlikely that the role for AcbSh in expression of extinction is due simply to nonspecific behavioral activation. AcbSh inactivation does not increase responding in self-administration paradigms. For example, inactivation of AcbSh has no effect on lever pressing for a second-order cue (Di Ciano et al., 2008), on lever pressing in a progressive ratio schedule (Zhang et al., 2003), or on acquisition of instrumental responding for food reward (Hanlon et al., 2004). In the present experiments, there were no differences between groups in latency to first nosepoke response. AcbSh inactivation also had no effect on responding when administered before extinction training. Extinction training was a requirement for detecting an effect of AcbSh inactivation in the present experiments. Nonetheless, there appeared to be an increase in inactive nosepoke responding on test after AcbSh inactivation. The increase in responding produced by AcbSh inactivation was greater for the active than inactive nosepoke. A similar increase in inactive nosepoke responding is typically observed during the first 
day of extinction training. It is reminiscent of the response enhancing effects of unexpected reward omission (Amsel, 1992) and raises the possibility that AcbSh contributes to behavioral inhibition more generally.

The role for AcbSh in inhibiting reward seeking after extinction depends, at least in part, on interactions with hypothalamus. AcbSh projects to $\mathrm{LH}$ with fewer projections to PeF and $\mathrm{DMH}$ (Heimer et al., 1991; Marchant et al., 2009), and AcbSh projections to $\mathrm{LH}$, but not $\mathrm{PeF}$, are active during extinction expression (Marchant et al., 2009). Furthermore, AcbSh projections are primarily GABAergic (Sano and Yokoi, 2007), and inhibition of AcbSh likely suppresses the release of GABA in LH, thereby disinhibiting LH (Stratford and Kelley, 1997). We and others (Stratford and Kelley, 1997, 1999; Zheng et al., 2003; Baldo et al., 2004) showed that inactivation of AcbSh increased LH c-Fos expression, although we and others (Zheng et al., 2003) also found increased c-Fos expression activation in medial hypothalamic regions. Importantly, concurrent LH inactivation prevented reinstatement induced by AcbSh inactivation, suggesting that reinstatement was dependent on LH. As bilateral inactivation of LH prevents contextinduced reinstatement of reward seeking and has no effect on non-reinstated responding (Marchant et al., 2009), it is unlikely that attenuation of reinstatement by concurrent inactivation of AcbSh and LH was caused by nonspecific motor deficits. Rather, our findings are consistent with the role of $\mathrm{LH}$ in mediating reinstatement (Harris et al., 2005; Marchant et al., 2009). Together, these findings suggest that AcbSh inhibits drug seeking after extinction through inhibitory control over LH. This AcbSh-LH pathway may be an interface through which extinction circuits converge with reinstatement circuits.

\section{Hypothalamic neuropeptides, extinction, and reinstatement} AcbSh inactivation increased c-Fos expression in orexin-neurons in $\mathrm{PeF}, \mathrm{LH}$, and $\mathrm{DMH}$. This is in agreement with previous reports of c-Fos expression in PeF/LH orexin neurons following AcbSh injections of muscimol (Zheng et al., 2003; Baldo et al., 2004) and cue-induced reinstatement of ethanol seeking Dayas et al., 2008). Orexin neurons in LH may mediate reward-related behaviors such as reinstatement, whereas orexin neurons in $\mathrm{DMH}$ and $\mathrm{PeF}$ may mediate arousal (Harris et al., 2005; Harris and Aston-Jones, 2006; Aston-Jones et al., 2009). DMH and PeF orexin neurons are activated during periods of wakefulness, whereas LH neurons show no such variation (Estabrooke et al., 2001). Furthermore, c-Fos expression in LH orexin cells, but not DMH or PeF, positively correlates with magnitude of context-induced reinstatement (Hamlin et al., 2007) and morphine conditioned place preference (Harris et al., 2005). Interestingly, we found that c-Fos induction in $\mathrm{DMH}, \mathrm{PeF}$, and $\mathrm{LH}$ orexin neurons were each correlated with reinstatement. AcbSh inactivation may have recruited both arousal and reinstatement pathways. To clarify these findings it will be important to achieve greater pharmacological specificity when manipulating AcbSh during extinction.

Reversible inactivation of AcbSh modestly increased expression of c-Fos-IR in CART-labeled cells in PeF, but not in LH or DMH. Dayas et al. (2008) did not detect this effect during reinstatement produced by an alcohol-associated discriminative stimulus. One possibility is that GABAergic inactivation of AcbSh recruits several circuits involved in arousal and reward. For example, inactivation of AcbSh increases food intake (Stratford and Kelley, 1997, 1999; Zheng et al., 2003) and food intake has been shown to be associated with increased expression of CART mRNA in medial and lateral parts of hypothalamus (Yu et al., 2008).
Orexin and CART neurons in $\mathrm{PeF} / \mathrm{LH}$ project to key substrates of the reward circuit: ventral tegmental area (VTA) (Fadel and Deutch, 2002; Philpot et al., 2005) and PVT (Kirouac et al., 2005, 2006). Both VTA and PVT have been implicated in reinstatement of extinguished reward seeking (Bossert et al., 2004; Aston-Jones et al., 2009; Hamlin et al., 2009) and PVT was recruited during reinstatement in the present experiments. PVT is of special interest due to its projections to regions implicated in reinstatement, including amygdala, hippocampus, and prefrontal cortex. PVT may "bind" or integrate neural circuits for reinstatement. We observed increased c-Fos-IR in PVT, BLA, and CeA. c-Fos induction in BLA supports the findings of Peters et al. (2008) that BLA is causally involved in reinstatement after inactivation of the prefrontal cortex. However, AcbSh does not project directly to BLA or CeA but does so indirectly via $\mathrm{LH}$ and PVT. Given the role of amygdala and prefrontal regions in reinstatement (McFarland et al., 2004; Alleweireldt et al., 2006; Feltenstein and See, 2007; Fuchs et al., 2007; McLaughlin and Floresco, 2007), it is possible that AcbSh inhibits drug seeking after extinction training via hypothalamic-PVT-amygdala/prefrontal pathways.

\section{Relationship between extinction of drug seeking and satiety}

One interesting implication of the present experiments is that there is overlap between extinction of drug seeking and satiety. AcbSh inactivation reinstates extinguished responding for drug rewards. It also induces feeding behavior in satiated rats in an LH-dependent manner (Maldonado-Irizarry et al., 1995; Stratford and Kelley, 1999). AcbSh AMPA receptors are likewise important for expression of extinction of drug seeking and satiety (Kelley and Swanson, 1997; Sutton et al., 2003). These findings suggest that extinction of drug seeking and satiety share common mechanisms.

The common link between extinction of drug seeking and satiety is not the inhibition of an orally consumed reward since the role for AcbSh in extinction is also observed in studies using intravenous cocaine (Sutton et al., 2003; Peters et al., 2008). Rather, we suggest that extinction of drug seeking may be achieved via co-opting ventral striatal-hypothalamic circuits for satiety. It is well documented that food deprivation increases sensitivity to the rewarding effects of LH electrical stimulation (Carr and Simon, 1984), augments drug self-administration (Comer et al., 1995), and reinstates extinguished drug seeking (Carroll, 1985; Shalev et al., 2000). Thus, just as reinstatement of drug seeking depends on orexigenic mechanisms (e.g., Harris et al., 2005; Aston-Jones et al., 2009), so too might extinction of drug seeking depend on anorexigenic mechanisms.

\section{References}

Alleweireldt AT, Hobbs RJ, Taylor AR, Neisewander JL (2006) Effects of SCH-23390 infused into the amygdala or adjacent cortex and basal ganglia on cocaine seeking and self-administration in rats. Neuropsychopharmacology 31:363-374.

Amsel A (1992) Frustration theory: an analysis of dispositional learning and memory. Cambridge, UK: Cambridge UP.

Aston-Jones G, Smith RJ, Moorman DE, Richardson KA (2009) Role of lateral hypothalamic orexin neurons in reward processing and addiction. Neuropharmacology 56:112-121.

Baldo BA, Gual-Bonilla L, Sijapati K, Daniel RA, Landry CF, Kelley AE (2004) Activation of a subpopulation of orexin/hypocretin-containing hypothalamic neurons by GABAA receptor-mediated inhibition of the nucleus accumbens shell, but not by exposure to a novel environment. Eur J Neurosci 19:376-386.

Bossert JM, Liu SY, Lu L, Shaham Y (2004) A role of ventral tegmental area 
glutamate in contextual cue-induced relapse to heroin seeking. J Neurosci 24:10726-10730.

Carr KD, Simon EJ (1984) Potentiation of reward by hunger is opioid mediated. Brain Res 297:369-373.

Carroll ME (1985) The role of food deprivation in the maintenance and reinstatement of cocaine-seeking behavior in rats. Drug Alcohol Depend 16:95-109.

Comer SD, Lac ST, Wyvell CL, Curtis LK, Carroll ME (1995) Food deprivation affects extinction and reinstatement of responding in rats. Psychopharmacology 121:150-157.

Crombag HS, Shaham Y (2002) Renewal of drug seeking by contextual cues after prolonged extinction in rats. Behav Neurosci 116:169-173.

Crombag HS, Bossert JM, Koya E, Shaham Y (2008) Context-induced relapse to drug seeking: a review. Philos Trans R Soc Lond B Biol Sci 363:3233-3243.

Dayas CV, McGranahan TM, Martin-Fardon R, Weiss F (2008) Stimuli linked to ethanol availability activate hypothalamic CART and orexin neurons in a reinstatement model of relapse. Biol Psychiat 63:152-157.

de Wit H, Stewart J (1981) Reinstatement of cocaine-reinforced responding in the rat. Psychopharmacology 75:134-143.

Di Ciano P, Robbins TW, Everitt BJ (2008) Differential effects of nucleus accumbens core, shell, or dorsal striatal inactivations on the persistence, reacquisition, or reinstatement of responding for a drug-paired conditioned reinforcer. Neuropsychopharmacology 33:1413-1425.

Estabrooke IV, McCarthy MT, Ko E, Chou TC, Chemelli RM, Yanagisawa M, Saper CB, Scammell TE (2001) Fos expression in orexin neurons varies with behavioral state. J Neurosci 21:1656-1662.

Fadel J, Deutch AY (2002) Anatomical substrates of orexin-dopamine interactions: lateral hypothalamic projections to the ventral tegmental area. Neuroscience 111:379-387.

Feltenstein MW, See RE (2007) NMDA receptor blockade in the basolateral amygdala disrupts consolidation of stimulus-reward memory and extinction learning during reinstatement of cocaine-seeking in an animal model of relapse. Neurobiol Learn Mem 88:435-444.

Floresco SB, McLaughlin RJ, Haluk DM (2008) Opposing roles for the nucleus accumbens core and shell in cue-induced reinstatement of foodseeking behavior. Neuroscience 154:877-884.

Fuchs RA, Eaddy JL, Su ZI, Bell GH (2007) Interactions of the basolateral amygdala with the dorsal hippocampus and dorsomedial prefrontal cortex regulate drug context-induced reinstatement of cocaine-seeking in rats. Eur J Neurosci 26:487-498.

Fuchs RA, Ramirez DR, Bell GH (2008) Nucleus accumbens shell and core involvement in drug context-induced reinstatement of cocaine seeking in rats. Psychopharmacology 200:545-556.

Hamlin AS, Newby J, McNally GP (2007) The neural correlates and role of D1 dopamine receptors in the renewal of extinguished alcohol-seeking. Neuroscience 146:525-536.

Hamlin AS, Clemens KJ, Choi EA, McNally GP (2009) Paraventricular thalamus mediates context-induced reinstatement (renewal) of extinguished reward seeking. Eur J Neurosci 29:802-812.

Hanlon EC, Baldo BA, Sadeghian K, Kelley AE (2004) Increases in food intake or food-seeking behavior induced by GABAergic, opioid, or dopaminergic stimulation of the nucleus accumbens: is it hunger? Psychopharmacology 172:241-247.

Harris GC, Aston-Jones G (2006) Arousal and reward: a dichotomy in orexin function. Trends Neurosci 29:571-577.

Harris GC, Wimmer M, Aston-Jones G (2005) A role for lateral hypothalamic orexin neurons in reward seeking. Nature 437:556-559.

Harris GC, Wimmer M, Randall-Thompson JF, Aston-Jones G (2007) Lateral hypothalamic orexin neurons are critically involved in learning to associate an environment with morphine reward. Behav Brain Res 183:43-51.

Heimer L, Zahm DS, Churchill L, Kalivas PW, Wohltmann C (1991) Specificity in the projection patterns of accumbal core and shell in the rat. Neuroscience 41:89-125.

Kalivas PW, Volkow ND (2005) The neural basis of addiction: a pathology of motivation and choice. Am J Psychiatry 162:1403-1413.

Kelley AE, Swanson CJ (1997) Feeding induced by blockade of AMPA and kainate receptors within the ventral striatum: a microinfusion mapping study. Behav Brain Res 89:107-113.

Kirouac GJ, Parsons MP, Li S (2005) Orexin (hypocretin) innervation of the paraventricular nucleus of the thalamus. Brain Res 1059:179-188.

Kirouac GJ, Parsons MP, Li S (2006) Innervation of the paraventricular nucleus of the thalamus from cocaine- and amphetamine-regulated transcript (CART) containing neurons of the hypothalamus. J Comp Neurol 497:155-165.

Lawrence AJ, Cowen MS, Yang H-J, Chen F, Oldfield B (2006) The orexin system regulates alcohol seeking in rats. Br J Pharmacol 148:752-759.

Maldonado-Irizarry CS, Swanson CJ, Kelley AE (1995) Glutamate receptors in the nucleus accumbens shell control feeding behavior via the lateral hypothalamus. J Neurosci 15:6779-6788.

Marchant NJ, Hamlin AS, McNally GP (2009) Lateral hypothalamus is required for context-induced reinstatement of extinguished reward seeking. J Neurosci 29:1331-1342.

McFarland K, Davidge SB, Lapish CC, Kalivas PW (2004) Limbic and motor circuitry underlying footshock-induced reinstatement of cocaine-seeking behavior. J Neurosci 24:1551-1560.

McLaughlin RJ, Floresco SB (2007) The role of different subregions of the basolateral amygdala in cue-induced reinstatement and extinction of food-seeking behavior. Neuroscience 146:1484-1494.

Paxinos G, Watson C (2005) The rat brain in stereotaxic coordinates. Amsterdam: Elsevier Academic.

Peters J, LaLumiere RT, Kalivas PW (2008) Infralimbic prefrontal cortex is responsible for inhibiting cocaine seeking in extinguished rats. J Neurosci 28:6046-6053.

Philpot KB, Dallvechia-Adams S, Smith Y, Kuhar MJ (2005) A cocaine-andamphetamine-regulated-transcript peptide projection from the lateral hypothalamus to the ventral tegmental area. Neuroscience 135:915-925.

Richards JK, Simms JA, Steensland P, Taha SA, Borgland SL, Bonci A, Bartlett SE (2008) Inhibition of orexin-1/hypocretin-1 receptors inhibits yohimbineinduced reinstatement of ethanol and sucrose seeking in Long-Evans rats. Psychopharmacology 199:109-117.

Sano H, Yokoi M (2007) Striatal medium spiny neurons terminate in a distinct region in the lateral hypothalamic area and do not directly innervate orexin/hypocretin- or melanin-concentrating hormone-containing neurons. J Neurosci 27:6948-6955.

Shalev U, Highfield D, Yap J, Shaham Y (2000) Stress and relapse to drug seeking in rats: studies on the generality of the effect. Psychopharmacology 150:337-346.

Stratford TR (2005) Activation of feeding-related neural circuitry after unilateral injections of muscimol into the nucleus accumbens shell. Brain Res 1048:241-250.

Stratford TR, Kelley AE (1997) GABA in the nucleus accumbens shell participates in the central regulation of feeding behavior. J Neurosci 17:4434-4440.

Stratford TR, Kelley AE (1999) Evidence of a functional relationship between the nucleus accumbens shell and lateral hypothalamus subserving the control of feeding behavior. J Neurosci 19:11040-11048.

Sutton MA, Schmidt EF, Choi K-H, Schad CA, Whisler K, Simmons D, Karanian DA, Monteggia LM, Neve RL, Self DW (2003) Extinctioninduced upregulation in AMPA receptors reduces cocaine-seeking behaviour. Nature 421:70-75.

Yoshida K, McCormack S, España RA, Crocker A, Scammell TE (2006) Afferents to the orexin neurons of the rat brain. J Comp Neurol 494: 845-861.

Yu Y, South T, Wang Q, Huang X-F (2008) Differential expression of hypothalamic CART mRNA in response to body weight change following different dietary interventions. Neurochem Int 52:1422-1430.

Zhang M, Balmadrid C, Kelley AE (2003) Nucleus accumbens opioid, GABAergic, and dopaminergic modulation of palatable food motivation: contrasting effects revealed by a progressive ratio study in the rat. Behav Neurosci 117:202-211.

Zheng H, Corkern M, Stoyanova I, Patterson LM, Tian R, Berthoud H-R (2003) Peptides that regulate food intake: appetite-inducing accumbens manipulation activates hypothalamic orexin neurons and inhibits POMC neurons. Am J Physiol Regul Integr Comp Physiol 284:R1436-R1444. 